\title{
OH clock determination by proton transfer reaction mass spectrometry at an environmental chamber
}

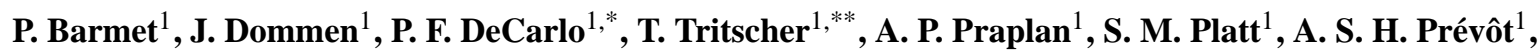 \\ N. M. Donahue ${ }^{2}$, and U. Baltensperger ${ }^{1}$ \\ ${ }^{1}$ Laboratory of Atmospheric Chemistry, Paul Scherrer Institute, Villigen, Switzerland \\ ${ }^{2}$ Center for Atmospheric Particle Studies, Carnegie Mellon University, Pittsburgh, PA, USA \\ * now at: Department of Civil Architectural and Environmental Engineering, Drexel University, Philadelphia, PA, USA \\ ** now at: TSI GmbH, Particle Instruments, Aachen, Germany
}

Correspondence to: J. Dommen (josef.dommen@psi.ch)

Received: 7 October 2011 - Published in Atmos. Meas. Tech. Discuss.: 15 December 2011

Revised: 6 March 2012 - Accepted: 11 March 2012 - Published: 29 March 2012

\begin{abstract}
The hydroxyl free radical $(\mathrm{OH})$ is the major oxidizing species in the lower atmosphere. Measuring the $\mathrm{OH}$ concentration is generally difficult and involves elaborate, expensive, custom-made experimental setups. Thus other more economical techniques, capable of determining $\mathrm{OH}$ concentrations at environmental chambers, would be valuable. This work is based on an indirect method of $\mathrm{OH}$ concentration measurement, by monitoring an appropriate $\mathrm{OH}$ tracer by proton transfer reaction mass spectrometry (PTRMS). 3-pentanol, 3-pentanone and pinonaldehyde (PA) were used as $\mathrm{OH}$ tracers in $\alpha$-pinene (AP) secondary organic aerosol (SOA) aging studies. In addition we tested butanold9 as a potential "universal" $\mathrm{OH}$ tracer and determined its reaction rate constant with $\mathrm{OH}: k_{\text {butanol-d } 9}=3.4( \pm 0.88) \times$ $10^{-12} \mathrm{~cm}^{3}$ molecule $\mathrm{s}^{-1} \mathrm{~s}^{-1}$. In order to make the chamber studies more comparable among each other as well as to atmospheric measurements we suggest the use of a chemical (time) dimension: the $\mathrm{OH}$ clock, which corresponds to the integrated $\mathrm{OH}$ concentration over time.
\end{abstract}

\section{Introduction}

The hydroxyl free radical $(\mathrm{OH})$ is the primary cleansing agent of the lower atmosphere (IPCC, 2007): it is the key reactant for the degradation of most compounds emitted from biogenic and anthropogenic sources into the troposphere (Ehhalt, 1999; Lelieveld et al., 2004). Globally OH radicals are mostly produced by photolysis of ozone $\left(\mathrm{O}_{3}\right)$ and the subsequent reaction of the formed excited oxygen atoms with water vapor. Minor sources include the photolysis of nitrous acid (HONO) and hydroperoxides, as well as the ozonolysis of alkenes. The major secondary $\mathrm{OH}$ source, i.e. from other radical species, is the reaction of nitric oxide (NO) with hydroperoxy radicals. Lifetimes of $\mathrm{OH}$ vary between $1 \mathrm{~s}$ and $10 \mathrm{~ms}$ in clean and polluted environments, respectively, due to the rapid reactions of $\mathrm{OH}$ with atmospheric trace gases (Schlosser et al., 2009).

Owing to its central importance, absolute measurements of $\mathrm{OH}$ concentrations are crucial and they are needed to determine the progress of photochemical aging. A useful metric is the photochemical age defined as $\mathrm{OH}$ exposure which can be used as a chemical clock (OH clock). The $\mathrm{OH}$ clock corresponds to the $\mathrm{OH}$ concentration integrated over time. This chemical time dimension makes experiments e.g. between different smog chambers more comparable than other widely used clocks such as "time after lights on" (TALO) or "time after start of secondary organic aerosol (SOA) formation" and has been applied already in other publications, e.g. Hennigan et al. (2010). Also for comparisons between lab studies and atmospheric measurements the $\mathrm{OH}$ clock is a fundamental parameter - especially since the photochemical age has been determined in many atmospheric studies.

Atmospheric $\mathrm{OH}$ is hard to measure (Brune, 1992), since low $\mathrm{OH}$ concentrations require extremely sensitive detection techniques and $\mathrm{OH}$ reacts efficiently at wall surfaces, requiring precautions to avoid instrumental $\mathrm{OH}$ loss. Another reason is that most other atmospheric species are much more abundant, raising the potential for interferences in $\mathrm{OH}$ detection. Furthermore, stable calibration mixtures for $\mathrm{OH}$ do not exist (Schlosser et al., 2009).

However, the large-scale concentrations and long-term trends of $\mathrm{OH}$ concentrations in the atmosphere can be 
inferred indirectly using global measurements of trace gases for which emissions are well known and their primary sink is the reaction with $\mathrm{OH}$. According to IPCC (2007), the best trace gas used to date for this purpose is methyl chloroform. Other gases that are useful $\mathrm{OH}$ indicators include ${ }^{14} \mathrm{CO}$, which is produced primarily by cosmic rays (Lowe and Allan, 2002). Another useful gas is the industrial chemical HCFC-22. It yields $\mathrm{OH}$ concentrations similar to those derived from methyl chloroform, but with less accuracy due to greater uncertainties in emissions and less extensive measurements (Miller et al., 1998). Indirect measurements of $\mathrm{OH}$ concentrations using methyl chloroform have established that the globally weighted average $\mathrm{OH}$ concentration in the troposphere is roughly $10^{6} \mathrm{~cm}^{-3}$ (Prinn, 2001; Krol and Lelieveld, 2003). A similar average concentration is derived using ${ }^{14} \mathrm{CO}$ (Quay et al., 2000).

Tropospheric $\mathrm{OH}$ was detected for the first time by Perner et al. (1976) using differential optical absorption spectroscopy (DOAS). Schlosser et al. (2009) report that the most widely applied $\mathrm{OH}$ concentration measurement technique is laser-induced fluorescence (LIF) combined with a gas expansion, also known as fluorescence assay with gas expansion (FAGE). LIF instruments directly measure $\mathrm{OH}$ concentrations with high sensitivity and can be built compact for mobile operation. Chemical ionization mass spectrometry (CIMS) is an $\mathrm{OH}$ concentration measurement technique with very high sensitivity and good mobility for ground and aircraft field campaigns comparable to LIF instruments (Eisele and Tanner, 1991; Berresheim et al., 2000). Long-term monitoring of $\mathrm{OH}$ concentrations has only been demonstrated using CIMS (Rohrer and Berresheim, 2006). OH concentration measurements using DOAS are currently only operated by researchers at the Jülich Forschungszentrum in field and chamber campaigns (Dorn et al., 1996; Brauers et al., 2001; Schlosser et al., 2007). According to Schlosser et al. (2009) all three techniques (DOAS, LIF, CIMS) involve elaborate, expensive, custom-made experimental setups. Therefore, worldwide less than ten research groups measure atmospheric $\mathrm{OH}$ concentrations using these techniques. Other techniques, e.g. the salicylic acid scavenger method (Salmon et al., 2004) or the radiocarbon tracer method (Campbell et al., 1986) do not have the degree of accuracy, sensitivity and time resolution provided by LIF, CIMS, and DOAS (Schlosser et al., 2009).

Many researchers over the last decades have used the VOC ratio method to determine average $\mathrm{OH}$ concentrations and its photochemical age in an air parcel. Calvert (1976) made the first indirect estimates of the average ambient concentration of the $\mathrm{OH}$ from the observed rates of removal of hydrocarbons of different $\mathrm{OH}$-reactivities. This concept of using reactive tracers to determine the $\mathrm{OH}$ concentration has been discussed (and improved) in several publications in the past, like e.g.: Singh et al. (1981); Roberts et al. (1984); McKeen et al. (1990); Satsumabayashi et al. (1992); Blake et al. (1993); McKenna et al. (1995);
Kramp and Volz-Thomas (1997). Other studies use the ratio of $\mathrm{NO}_{2}$ to $\mathrm{NO}_{\mathrm{y}}$ to determine the photochemical age (Kleinman et al., 2008; Slowik et al., 2011).

These ambient measurements emphasize the need of using the $\mathrm{OH}$ clock also in smog chamber studies - as this has just begun to be done in the last few years. Based on the findings of Poppe et al. (2007) at the SAPHIR chamber in Jülich, this indirect technique works also at environmental chambers. The decay of several hydrocarbons by hydroxyl radicals was measured with gas chromatography and proton transfer reaction mass spectrometry (PTR-MS, described by Lindinger et al., 1998) while the $\mathrm{OH}$ was measured with DOAS. The combination of these measurements yielded reaction rate constants in good agreement with the reference rate constants taken from the Master Chemical Mechanism (MCM3.1).

Direct $\mathrm{OH}$ concentration measurement in chambers are difficult to maintain over long time periods, as for most $\mathrm{OH}$ measurement techniques (except DOAS) very high flow rates are required. Also, most species reacting with $\mathrm{OH}$ in chambers have lifetimes of many minutes to hours and thus the chamber-averaged $\mathrm{OH}$ concentration must be known. $\mathrm{OH}$ is likely not uniform in most chambers, and in situ methods like LIF or CIMS will not necessarily constrain this average.

Against this background, a method of feasibly determining $\mathrm{OH}$ concentrations with instruments commonly installed at environmental chambers would be highly valuable. One possibility in this context is the use of an adequate $\mathrm{OH}$ tracer that can be monitored by PTR-MS. Changes in the tracer concentration over time can be expressed as:

$\frac{\mathrm{d}[\text { tracer }]}{\mathrm{d} t}=-k \cdot[\mathrm{OH}] \cdot[$ tracer $]$

In the case of constant $\mathrm{OH}$ concentration levels, one can integrate Eq. (1) to get Eq. (2):

$\ln ([$ tracer $])=-k \cdot[\mathrm{OH}] \cdot t+\ln \left([\operatorname{tracer}]_{0}\right)$

Plotting the natural logarithm $(\mathrm{ln})$ of the tracer concentration versus time $(t)$, results in a slope that equals $-k \cdot[\mathrm{OH}]$. The $\mathrm{OH}$ concentration is therefore:

$[\mathrm{OH}]=\frac{- \text { slope }}{k}$

In order to use a direct oxidation product of the reaction of a reagent with $\mathrm{OH}$ as an $\mathrm{OH}$ tracer, one has to modify Eq. (2), using the relation between the amount of the reacted reagent and the produced product:

[product $] \cdot q=[\text { reagent }]_{0}-[$ reagent $]$

Where $q$ is the proportionality factor between the "reagent reacted" and the "product produced" by the reaction with $\mathrm{OH}$.

The analogous of Eq. (2) would then be:

$\ln \left(1-\frac{[\text { product }]}{[\text { reagent }]_{0} / q}\right)=-k \cdot[\mathrm{OH}] \cdot t$ 
Plotting the left side of Eq. (5) versus time $(t)$, results in a slope that equals $-k \cdot[\mathrm{OH}]$. The $\mathrm{OH}$ concentration is then calculated again with Eq. (3).

In our case, the ideal $\mathrm{OH}$ tracer has to be detectable by PTR-MS (which requires that its proton affinity is higher than the one of water), reacts only with $\mathrm{OH}$ and has no interference with other compounds at the tracer's mass-to-charge ratio $(\mathrm{m} / \mathrm{z})$. The last point pertains mainly to an instrument with a quadrupole mass spectrometer at unit mass resolution. Furthermore the tracer should exhibit a certain reactivity (neither too fast nor too slow) such that changes in concentration during the course of an experiment are measurable.

In this paper, we discuss three $\mathrm{OH}$ tracers which were used to determine the $\mathrm{OH}$ concentration during an $\alpha$-pinene (AP) ozonolysis and aging campaign where we suggest the use of an $\mathrm{OH}$ based dimension: the $\mathrm{OH}$ clock. Furthermore a new, deuterated $\mathrm{OH}$ tracer for PTR-MS is presented, together with the investigation of its reaction rate constant with $\mathrm{OH}$. This deuterated $\mathrm{OH}$ tracer exhibits a characteristic $\mathrm{m} / \mathrm{z}$ unlikely to interfere with any other compounds.

\section{Experimental setup}

\subsection{MUCHACHAS}

The Multiple Chamber Aerosol Chemical Aging Study (MUCHACHAS) was designed to test the hypothesis that hydroxyl radical oxidation significantly alters the levels and properties of SOA (Donahue et al., 2012). The typical design of a MUCHACHAS experiment is shown as schematic in Fig. 1 (see also Tritscher et al., 2011). The precursor in all experiments was AP. This precursor first reacted with $\mathrm{O}_{3}$ to form SOA. Then, after nearly all the precursor was consumed, this SOA and partially oxidized gas-phase species were exposed to $\mathrm{OH}$ from different sources in order to observe additional production and aging of SOA by $\mathrm{OH}$. The overall results of the MUCHACHAS campaign are presented in Donahue et al. (2012), and only a short summary on the experimental details is given here (see also Tritscher et al., 2011).

In all experiments, the clean PSI smog chamber - described in Paulsen et al. (2005) - was humidified to $\sim 50 \%$ $\mathrm{RH}$ and $\mathrm{O}_{3}$ was added in a first step. After about $20 \mathrm{~min}$, when $\mathrm{O}_{3}$ was homogeneously distributed in the chamber, the precursor AP was injected. We conducted experiments at two atmospherically relevant precursor mixing ratios of $40 \mathrm{ppb}$ and $10 \mathrm{ppb}$ AP. The reaction started immediately via ozonolysis of the $\mathrm{C}=\mathrm{C}$ double bond in $\mathrm{AP}$, forming particles (first generation SOA). The $\mathrm{OH}$ formed by the ozonolysis will mainly react with AP, as long as it is still present in excess. Ozonolysis lasted a few hours until at least $90 \%$ of the AP precursor had reacted. This phase is subdivided into a $\mathrm{O}_{3}$ induced condensation and a ripening period (see Fig. 1).

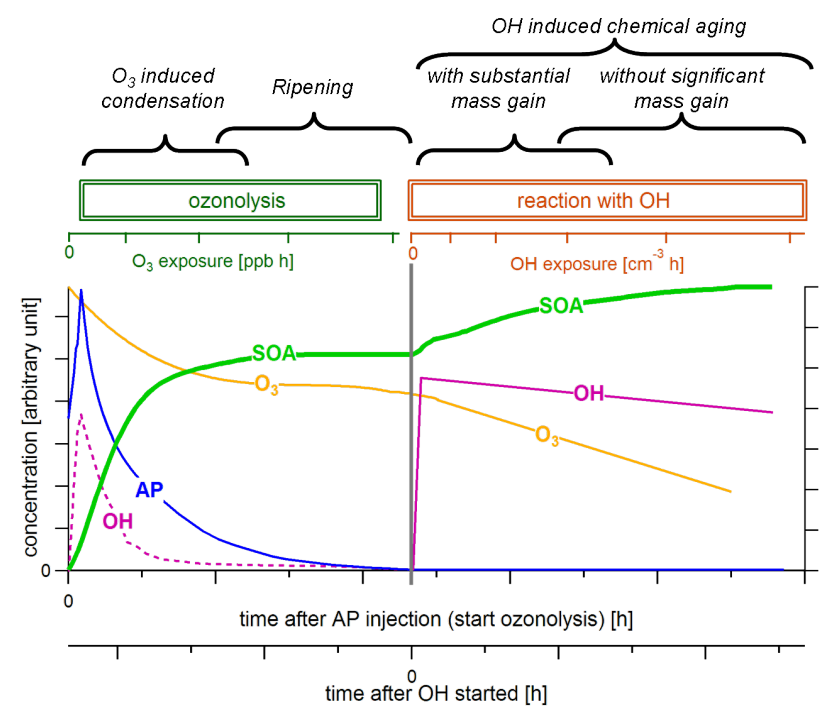

Fig. 1. Schematic of the experiments during the MUCHACHAS campaign at the PSI smog chamber. Formation of secondary organic aerosol (SOA) mass (wall-loss corrected) from the volatile organic precursor $\alpha$-pinene (AP) takes place during the first part in the dark with ozone $\left(\mathrm{O}_{3}\right)$. The aging of the SOA and gaseous products from ozonolysis was then investigated under different conditions. The data can be plotted against several time axes as "time after AP injection was started" and "time after the $\mathrm{OH}$ reaction started" or against a "chemical clock" as $\mathrm{O}_{3}$ exposure and $\mathrm{OH}$ exposure. During ozonolysis and reaction with $\mathrm{OH}$ the four different periods of our experiments are indicated above the figure: $\mathrm{O}_{3}$ induced condensation, ripening, $\mathrm{OH}$ induced chemical aging with substantial mass gain, and $\mathrm{OH}$ induced chemical aging without significant mass gain (reproduced from Tritscher et al., 2011).

In a next step, $20 \mathrm{ppb}$ of 3-pentanol was added as an $\mathrm{OH}$ tracer. Then SOA was aged by exposure to $\mathrm{OH}$ generated from either photolysis of HONO or ozonolysis of tetramethylethylene (TME) (IUPAC name: 2,3-dimethyl2-butene) (Epstein and Donahue, 2008). A HONO level of $15-20 \mathrm{ppb}$ (as measured by a long path absorption photometer; LOPAP) in the chamber was reached by passing pure air $\left(21 \mathrm{~min}^{-1}\right)$ through a custom built vessel containing sulfuric acid $\left(0.01 \mathrm{M} \mathrm{H}_{2} \mathrm{SO}_{4}\right)$ and sodium nitrite $\left(3 \times 10^{-3} \mathrm{M}\right.$ $\mathrm{NaNO}_{2}$ ). The vessel and the HONO system are described elsewhere (Taira and Kanda, 1990). The flow from the HONO generator was passed through a filter to ensure that only the gas phase HONO without particles entered into the chamber. The addition of HONO started about one hour before the lights were turned on. The goal was to perform these experiments in a low- $\mathrm{NO}_{\mathrm{x}}$ regime. In contrast, for some high- $\mathrm{NO}_{\mathrm{x}}$ photolysis experiments, 50-80 ppb NO was added aside from HONO. For OH experiments in the dark, TME was continuously injected from a gas cylinder (Messer, TME 1000 ppmv in $\mathrm{N}_{2} 5.0$ ) at a flow of $10 \mathrm{ml} \mathrm{min}^{-1}$. The $\mathrm{O}_{3}$ level was usually chosen to be higher in the TME experiments compared to $\mathrm{HONO}$ photolysis experiments because $\mathrm{O}_{3}$ was 
also consumed by the ozonolysis of TME. This second phase of the experiment, i.e. reaction and aging with $\mathrm{OH}$ could be divided into an $\mathrm{OH}$ induced chemical aging with and without significant mass gain (see Fig. 1).

The $\mathrm{OH}$ concentration in the environmental chamber was derived from the decay of 3-pentanol and from a specific intermediate product of AP and pentanol oxidation. In total, the following three $\mathrm{OH}$ tracers were tested:

- 3-pentanol, which was injected additionally,

- the formation of 3-pentanone (also named diethyl ketone), a direct oxidation product of the reaction of 3-pentanol with $\mathrm{OH}$,

- pinonaldehyde (PA), an ozonolysis product of AP.

The $\mathrm{OH}$ concentration integrated over time is used as a chemical clock to bring all experiments on a comparable time scale. One application of the $\mathrm{OH}$ clock for the MUCHACHAS campaign has been published by Tritscher et al. (2011). The rate constants used to calculate $\mathrm{OH}$ concentrations and the $\mathrm{OH}$ clocks were: $k_{3 \text {-pentanol }}(298.15 \mathrm{~K})=1.22 \times 10^{-11} \mathrm{~cm}^{3}$ molecule $^{-1} \mathrm{~s}^{-1}$ (Wallington et al., 1988) for 3-pentanol and $k_{\mathrm{PA}}(298.15 \mathrm{~K})=$ $3.9 \times 10^{-11} \mathrm{~cm}^{3}$ molecule ${ }^{-1} \mathrm{~s}^{-1}$ (IUPAC, 2011) for PA.

\subsection{Butanol-d9}

The mass spectra in PTR-MS show generally low signal intensities at even mass-to-charge ratios $(\mathrm{m} / \mathrm{z})$ due to the protonation of the compounds $\left(\mathrm{M}+\mathrm{H}^{+}\right)$. Owing to its unusual mass-to-charge ratio $\left(\mathrm{m} / \mathrm{z} 66,\left[\mathrm{M}+\mathrm{H}-\mathrm{H}_{2} \mathrm{O}\right]^{+}\right), 9$-fold deuterated butanol (butanol-d9; n-butanol (D9, 98\%); IUPAC name: $\left[1,1,2,2,3,3,4,4,4-{ }^{2} \mathrm{H}_{9}\right]$ Butan-1-ol) promises to be a

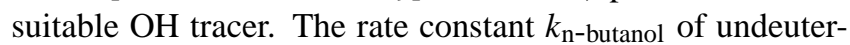
ated n-butanol with $\mathrm{OH}$ is quite well known (according to IUPAC the reliability is $\Delta \log (k)= \pm 0.15$ at $298 \mathrm{~K}$; IUPAC, 2011), however, due to the kinetic isotope effect (KIE) it differs from the k-value of deuterated butanol. The investigation of the rate constant of butanol-d9 with $\mathrm{OH}$ was done relative to the well known k-value (reliability: $\Delta \log (k)= \pm 0.1$ at $298 \mathrm{~K}$; IUPAC, 2011) of 2-butanone (also named methyl ethyl ketone) as a reference compound. Additionally we injected the "MUCHACHAS-tracer" (3-pentanol).

The experiments were performed at the PSI smog chamber and the $\mathrm{OH}$ tracers were monitored by PTR-MS with a quadrupole detector. Butanol-d9, 2-butanone and 3-pentanol were injected in 20 to $30 \mathrm{~min}$ time intervals - in order to ensure homogeneous distribution in the chamber - and they all had a mixing ratio of approximately $20 \mathrm{ppb}$. As an $\mathrm{OH}$ source, HONO plus light was used - similar to the MUCHACHAS HONO photolysis experiments: the addition of HONO started one hour before the lights were turned on, reaching a level of approximately $15 \mathrm{ppb}$. In order to enhance the $\mathrm{OH}$ concentration - and unlike during the MUCHACHAS campaign - additional UV lights were used (black lights emitting mainly between 320 and $400 \mathrm{~nm}$; manufactured by Cleo Performance; in total 80 tubes with $100 \mathrm{~W}$ per tube).

\section{Results and discussion}

\subsection{MUCHACHAS}

Figure 2 shows the time trends of $\mathrm{AP}$ and the three potential $\mathrm{OH}$ tracers during a MUCHACHAS experiment with HONO as $\mathrm{OH}$ source (with additional NO). After injection, AP rapidly decays due to ozonolysis and produces among other products PA (observed as $m / z 151,\left[\mathrm{M}+\mathrm{H}-\mathrm{H}_{2} \mathrm{O}\right]^{+}$). Subsequently 3-pentanol $\left(\mathrm{m} / z 71,\left[\mathrm{M}+\mathrm{H}-\mathrm{H}_{2} \mathrm{O}\right]^{+}\right)$is injected before the start of $\mathrm{OH}$ production. Thereafter $\mathrm{m} / \mathrm{z} 71$ and $\mathrm{m} / \mathrm{z}, 151$ decrease while the pentanol oxidation product 3-pentanone $(\mathrm{m} / \mathrm{z}, 87)$ is produced.

Figure 2 indicates the disadvantage of 3-pentanol (red line) as an $\mathrm{OH}$ tracer: during the ozonolysis of $\mathrm{AP}$, one or more compounds are produced appearing at the signal $\mathrm{m} / \mathrm{z} 71$ of 3-pentanol. Several AP ozonolysis experiments (without adding 3-pentanol, not shown in Fig. 2) revealed that one fraction of the ozonolysis products at $\mathrm{m} / \mathrm{z}, \mathrm{r}$ reacted away as soon as the $\mathrm{OH}$ source was turned on, while another fraction did not and appeared to remain at a constant level. The decreasing fraction could be a fragment of PA and leads to a systematic overestimation of the $\mathrm{OH}$ concentration - most notably right after the $\mathrm{OH}$ production starts.

For PA there is no known interference with other compounds at $m / z=151$. One of the biggest advantages of PA is that it is present in all the AP ozonolysis experiments and does not require additional injections. However, a major disadvantage of PA is that it reacts almost four times faster with $\mathrm{OH}$ than 3-pentanol. Furthermore the initial PA concentration depends on the initial AP concentration. Therefore this tracer is not ideal for longer experiments with high $\mathrm{OH}$ concentrations - especially when the initial AP concentration is low. Another drawback of PA and pentanone, which cannot be seen from Fig. 2, is that some other reactions may interfere: PA reacts with $\mathrm{NO}_{3}$ and undergoes photolysis, while pentanone photolyzes as well and is decomposed by the reaction with $\mathrm{OH}$. However, these superposing reactions are very slow and should not significantly influence the $\mathrm{OH}$ concentration determination. PA has little utility in experiments where not all AP is consumed prior to the onset of $\mathrm{OH}$ production since it is still formed (at $\mathrm{m} / \mathrm{z} 151$ ) while one would like to determine the $\mathrm{OH}$ concentration from the decay of its $\mathrm{m} / \mathrm{z}$ signal.

The interference at pentanone's $m / z 87$ is quite small. However experiments without 3-pentanol addition revealed that just after the ozonolysis of AP the signal of $m / z 87$ in PTR-MS jumps up to a higher level and remains constant until the lights are turned on, from where on a further increase in the signal is monitored. The initial signal, before 


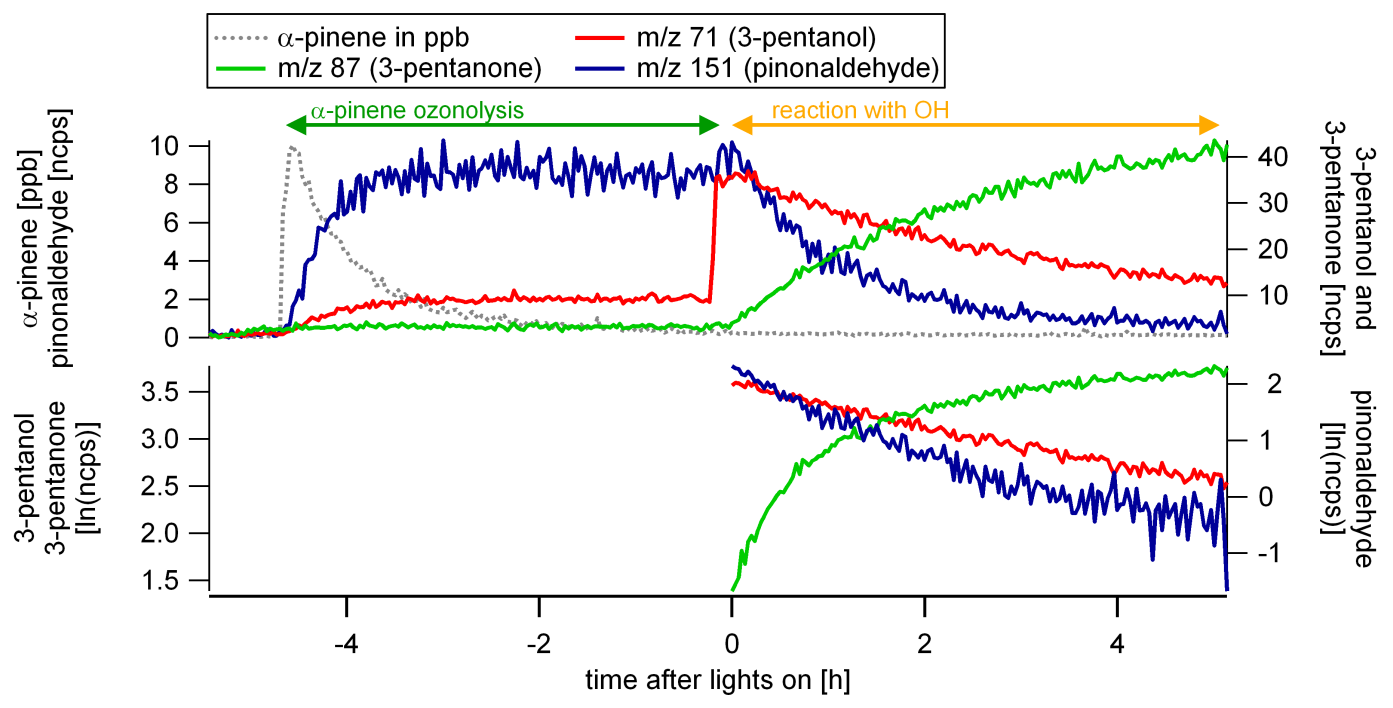

Fig. 2. Three potential OH tracers measured by PTR-MS and used for the OH concentration determination during the MUCHACHAS campaign at the PSI smog chamber. The unit of the tracers is normalized counts per second (ncps) while the unit of $\alpha$-pinene (grey dots) is parts per billion (ppb). The apparent 3-pentanol signal (red line, $\mathrm{m} / \mathrm{z}$ 71) increases already during the ozonolysis of $\alpha$-pinene and indicates an interference with other compounds. 3-pentanone (green line) is a direct oxidation product of 3-pentanol with $\mathrm{OH}$ and is monitored at $m / z=87$. Pinonaldehyde (blue line, $m / z$ 151) is an ozonolysis product of $\alpha$-pinene and reacts several times faster with OH than 3-pentanol. The pinonaldehyde concentration depends on the initial $\alpha$-pinene concentration. A few hours after the $\mathrm{OH}$ source has been turned on, the pinonaldehyde is generally depleted. The lower panel presents the signal on a log-scale.

turning the $\mathrm{OH}$ source on, can easily be subtracted, but the increase during the time where the $\mathrm{OH}$ is produced continuously is difficult to handle. Nevertheless this later interference is very small and it is partly compensated by the above mentioned superposed reactions. In summary 3-pentanone is a convenient $\mathrm{OH}$ tracer, but due to the mentioned issues and the fact that it includes some intermediate steps (such as the determination of the the proportionality factor between "3-pentanol reacted" and "3-pentanone produced"), which are all potential sources of errors, it might not be the first choice $\mathrm{OH}$ tracer.

As is seen from the lower panel of Fig. 2 - from a $10 \mathrm{ppb}$ AP experiment - the decay of $\ln ([\mathrm{PA}])$ and $\ln ([3$-pentanol] $)$ is not linear on a logarithmic scale. This is either due to an interference with other compounds at the tracer's specific $\mathrm{m} / \mathrm{z}$ or due to interfering reactions, or it indicates that the $\mathrm{OH}$ concentration is not constant over the course of the experiment. Eq. (3) cannot be applied. Thus, dealing only with slowly changing $\mathrm{OH}$ concentrations over time, the evolution of $\ln ([\mathrm{PA}])$ versus time was first fitted with an exponential function and then its derivative was used to calculate the slope at each point, as shown exemplarily in Fig. 3. The calculated $\mathrm{OH}$ concentrations agreed well with those modeled with version 3.1 of the Master Chemical Mechanism (MCMv3.1) (Jenkin and Hayman, 1999; Saunders et al., 2003). The OH concentrations based on 3-pentanol and 3-pentanone were additionally inserted in Fig. 3, which shows a 40 ppb AP experiment. While $\mathrm{OH}$ concentrations derived from pentanone are similar to those from PA, 3-pentanol as an $\mathrm{OH}$ tracer shows a large discrepancy.

$\mathrm{OH}$ clocks from all three tracers were produced using an exponential fit on the data. This is not a universal solution for all cases, but it seemed to work best in most of our experiments. Comparing the $\mathrm{OH}$ clocks $4 \mathrm{~h}$ after the $\mathrm{OH}$ source was turned on, there is - in the high AP experiments - a clear discrepancy between 3-pentanone and PA on the one side and 3-pentanol on the other. In these experiments with an AP mixing ratio of about $40 \mathrm{ppb}$ the discrepancy between the $\mathrm{OH}$ clocks could be more than a factor of two. In contrast, for the low AP experiments (about $10 \mathrm{ppb}$ AP) they still concur within $33 \%$ (calculated relative to PA) even $4 \mathrm{~h}$ after lights on. The increasing discrepancy over time between the tracers can be explained by the fact that after $4 \mathrm{~h}$ the tracer PA was usually consumed. It is obvious that PA is a more suitable $\mathrm{OH}$ tracer for AP ozonolysis experiments with a high initial AP concentration. Conversely, since PA is produced from AP, for experiments with an initial AP mixing ratio well below $10 \mathrm{ppb}$, PA is unsuitable as a tracer, unless more sensitive methods for PA determination can be used.

The extent to which the $\mathrm{OH}$ concentration determination is limited by this low concentration of the fast reacting PA and the interference at $\mathrm{m} / \mathrm{z} 71 \mathrm{can}$ be underlined by a result of another experiment, where the 3-pentanol was injected after the PA (and the interfering compounds at $m / z 71$ ) had reacted: during this three-day experiment, the SOA formation started every day with the ozonolysis of $40 \mathrm{ppb}$ AP without 


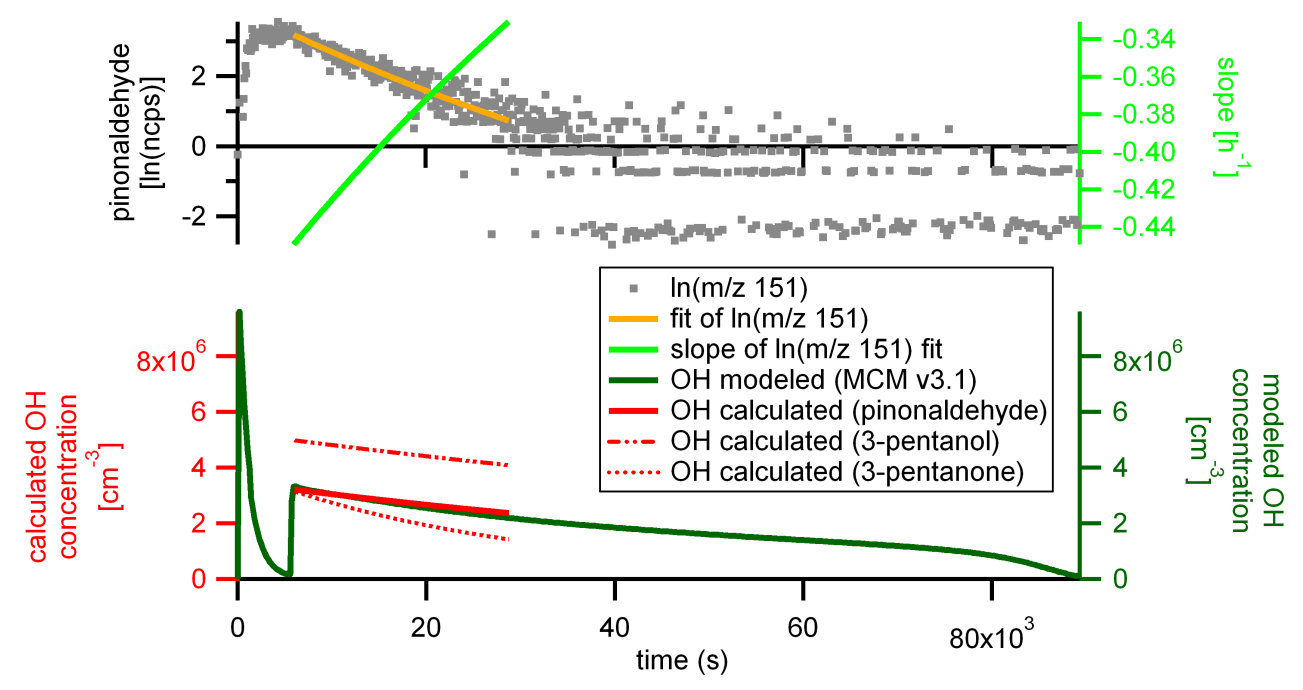

Fig. 3. Determination of the $\mathrm{OH}$ concentration from pinonaldehyde $(\mathrm{m} / \mathrm{z}, 151)$ under varying $\mathrm{OH}$ levels. The upper plot shows the $\ln (\mathrm{m} / \mathrm{z}, 151)$ decay measured by the PTR-MS (gray dots) and a fit (orange line) to the data, while the bright green line represents the slope of the fitted curve at each time point. The lower panel shows a comparison between the calculated (red) and modeled (dark green) OH concentration. The experiment lasted more than $24 \mathrm{~h}$, the initial $\alpha$-pinene mixing ratio was about $40 \mathrm{ppb}$ and the $\mathrm{OH}$ was produced from the ozonolysis of tetramethylethylene.

cleaning the chamber in between. Based on the PA tracer the $\mathrm{OH}$ concentration was very stable from the second day on. In order to avoid interference from other compounds at $\mathrm{m} / \mathrm{z} 71$, the 3-pentanol was injected $6.5 \mathrm{~h}$ after lights on. At that time all the interfering compounds were depleted and the determined $\mathrm{OH}$ concentration based on 3-pentanol was in quite good agreement with that based on the PA tracer: it was higher by less than $18 \%$ when compared to the PA tracer.

This discussion makes it clear that 3-pentanol, 3-pentanone and PA have clear drawbacks, and a "universal" $\mathrm{OH}$ tracer, which could also be applied in very complex systems - such as diesel car exhaust or two-stroke moped exhaust (see below) - is still needed.

We conclude that for the MUCHACHAS campaign 3-pentanone and PA as determined by PTR-MS are useful $\mathrm{OH}$ tracers while 3-pentanol is more problematic - especially for experiments with a higher AP concentration. The $\mathrm{OH}$ clocks based on 3-pentanone and PA agree quite well during the first $4 \mathrm{~h}$ after turning on the $\mathrm{OH}$ source. For experiments with a lower AP concentration all three tracers seem to concur quite well. In any case they all definitively do have clear drawbacks and none of them is useful for long experiments with a high $\mathrm{OH}$ dose.

\subsection{Butanol-d9}

Figure 4 shows three $m / z$, measured by PTR-MS during two moped exhaust oxidation experiments, which could be of interest as potential $\mathrm{OH}$ tracers. Figure $4 \mathrm{a}$ relates to a EURO1 moped and Fig. 4b to a EURO2 moped (both two-stroke engines). The signal at $m / z 62,64$ and 66 would interfere with
5-, 7-, or 9-fold deuterated butanol, respectively. At $m / z=66$ there is hardly any signal, not even after $20 \mathrm{~h}$ of experiment (Fig. 4a). Similar results were found for the exhaust from a four-stroke EURO2 moped, a diesel car and even wood burning (all not shown). Therefore, the 9-fold deuterated butanol is adequate also for such complex gas mixtures.

The rate constant of butanol-d9 with $\mathrm{OH}$ was determined using 2-butanone as a reference compound. 2-butanone is observed at $m / z=73$. Similarly, we also repeated the evaluation of the rate constant of 3-pentanol with this method. Kinetic data can be obtained using the expression

$\ln \left(\frac{[\text { tracer }]_{0}}{[\text { tracer }]_{t}}\right)=\frac{k_{\text {tracer }}}{k_{\text {reference }}} \cdot \ln \left(\frac{[\text { reference }]_{0}}{[\text { reference }]_{t}}\right)$

where [reference $]_{0}$ and [tracer $]_{0}$ correspond to the measured initial concentration of the reference and the tracer compound, respectively.

Figure 5 shows the results from two similar experiments with $20 \mathrm{ppb}$ of 2-butanone, 3-pentanol and butanol-d9 each. From the slopes (which correspond to the ratios of the rate constants) it can be concluded that the rate constant of 2-butanone with $\mathrm{OH}$ is about three times lower than the one of butanol-d9, and almost 10 times lower than the one of 3-pentanol. The slopes of linear least-squares analyses of the individual and the combined data sets of both experiments are summarized in Table 1 together with the rate constants for butanol-d9 and 3-pentanol. The fit uncertainty in Table 1 indicates the $95 \%$ confidence level. This also applies to the reliability confidence interval for the reference compound 2-butanone. As the fit uncertainty is very small, the confidence bands would overlap on the fitting line in Fig. 5. 

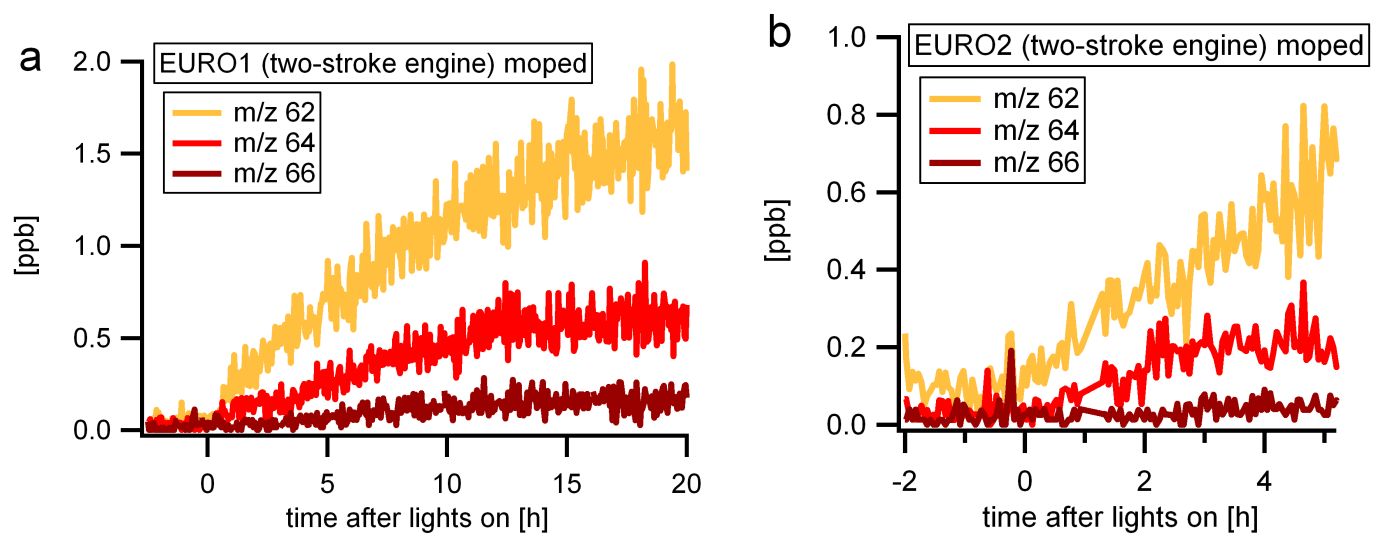

Fig. 4. Mass-to-charge ratios for potential OH tracers during a EURO1 (a) and a EURO2 (b) moped experiment monitored by PTR-MS. The mass-to-charge ratios 62, 64, and 66 would correspond to 5-, 7- or 9-fold deuterated butanol. The unit (ppb) is calculated assuming a proton transfer rate constant of $2 \times 10^{-9} \mathrm{~cm}^{3} \mathrm{~s}^{-1}$ as a default value.

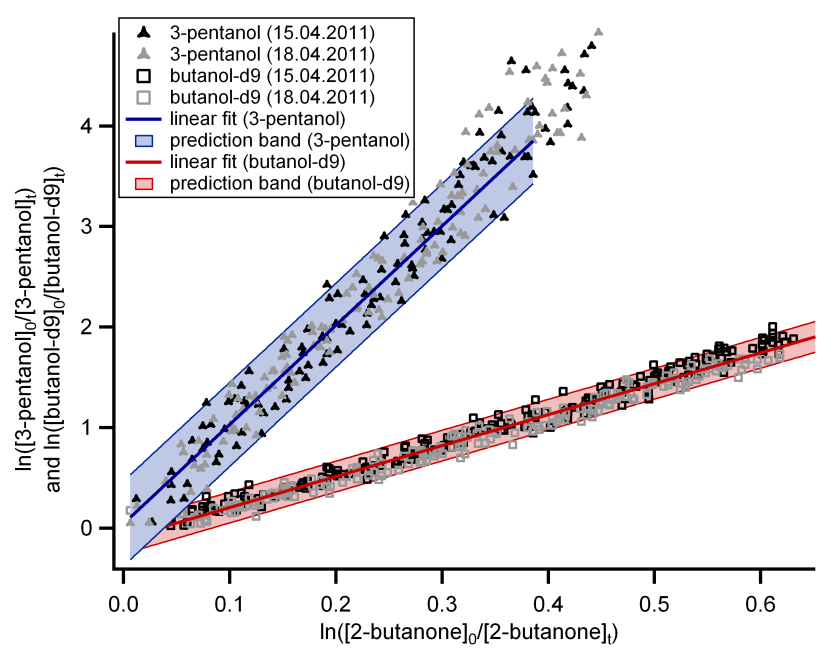

Fig. 5. OH tracers butanol-d9 and 3-pentanol versus the reference compound (2-butanone). The slopes represent the ratios of the rate constants of the considered $\mathrm{OH}$ tracers (butanol-d9 and 3-pentanol) plus $\mathrm{OH}$ and the reference compound (2-butanone) plus $\mathrm{OH}$. Table 1 gives an overview of the slopes and the resulting $k_{\mathrm{OH}}$-values for butanol-d 9 and 3-pentanol. The bright colors (red and blue) indicate the prediction bands of the fit on a $95 \%$ confidence level. The confidence bands would overlap with the fit and are therefore not shown here.

Therefore, we show the prediction bands on a $95 \%$ confidence level and not the confidence bands.

Using the IUPAC recommended $\mathrm{k}$-value of $1.106 \times$ $10^{-12} \mathrm{~cm}^{3}$ molecule ${ }^{-1} \mathrm{~s}^{-1}$ (from $k_{2}$-butanone $=1.5 \times 10^{-12} \times$ $e^{-90 / T}$ at $T=295.15 \mathrm{~K}$ ) for 2-butanone and taking the slopes through both data sets (in each case) results in $k_{\text {butanol-d } 9}=3.4( \pm 0.88) \times 10^{-12} \mathrm{~cm}^{3}$ molecule $^{-1} \mathrm{~s}^{-1}$ and $1.09( \pm 0.29) \times 10^{-11} \mathrm{~cm}^{3}$ molecule ${ }^{-1} \mathrm{~s}^{-1}$ for 3-pentanol (Table 1).
For butanol and its 9-fold deuterated analog (butanol-d9) we obtain a KIE of $2.5 \quad\left(\frac{k_{\mathrm{h}}}{k_{\mathrm{d}}}=2.5( \pm 1.2)\right)$ using $k_{\mathrm{n} \text {-butanol }}=8.52( \pm 3.51) \times 10^{-12} \mathrm{~cm}^{3}$ molecule $\mathrm{e}^{-1} \mathrm{~s}^{-1} \quad$ (IUPAC, 2011). This is very much in line with the fundamental primary KIE of about 2.8 derived for $\mathrm{H}$-abstractions by $\mathrm{OH}$ with a minimal reaction barrier height (Sage and Donahue, 2005). Our rate constant for pentanol is $9 \%$ lower than reported by Wallington et al. (1988), who measured it using an absolute technique, and $17 \%$ lower than the one of Hurley et al. (2008), who also used a relative technique. The main reason for this bigger discrepancy probably comes from using different reference compounds, which then again do have differing rate constants from literature. Hurley et al. (2008) used for one of their two reference compounds $\left(\mathrm{C}_{2} \mathrm{H}_{4}\right)$ a rate constant that is almost $8 \%$ higher than the preferred values from IUPAC (IUPAC, 2011).

However, the reference compound used here also has a few drawbacks: 2-butanone reacts quite slowly with $\mathrm{OH}$. This might result in a slightly increased uncertainty for the determined $k_{\text {butanol-d } 9 \text {. Furthermore it photolyzes. This systematic }}$ error might also explain to some extent the slightly lower

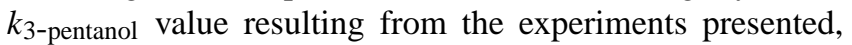
compared to those reported by Wallington et al. (1988) and Hurley et al. (2008). Even though according to the MCM model simulation for the PSI smog chamber and assuming that the photolysis rate of 2-butanone is not more enhanced by the new UV lamps than the photolysis rate of $\mathrm{O}_{3}$, the photolysis should not be responsible for more than $5 \%$ of the 2-butanone decay. This is especially true as the absorption cross section of 2-butanone - as reported by Martinez et al. (1992) - has its maximum at a wavelength of $295 \mathrm{~nm}$ and gets very low in the UVA range above $315 \mathrm{~nm}$. This error estimation is based on a conservative $\mathrm{OH}$ concentration assumption of $2.5 \times 10^{7} \mathrm{~cm}^{-3}$, while the determined $\mathrm{OH}$ concentration was about $15 \%$ higher. An experiment designed to determine the photolysis rate of butanone at the 
Table 1. Slopes of the linear regression fit lines shown in Fig. 5. The two columns on the right side contain the resulting absolute rate constants $\left(k_{3 \text {-pentanol }}\right.$ and $\left.k_{\text {butanol-d9 }}\right)$ for the reaction of 3-pentanol and butanol-d 9 with $\mathrm{OH}$ by using 2 -butanone $\left(k_{2}\right.$-butanone $=1.103 \times$ $10^{-12} \mathrm{~cm}^{3}$ molecule $\mathrm{s}^{-1} \mathrm{~s}^{-1}$ ) as a reference compound. The uncertainties are given in parentheses and represent the $95 \%$ confidence interval. For the $k_{\mathrm{OH}^{-}}$-values they are obtained by calculating the error propagation from the fit uncertainties and the reliability of the reference compound.

\begin{tabular}{|c|c|c|c|c|}
\hline \multirow{2}{*}{ Date } & \multicolumn{2}{|c|}{ Slope of the linear regression fit line } & \multicolumn{2}{|c|}{$k_{\mathrm{OH}}(295 \mathrm{~K})\left[10^{-12} \mathrm{~cm}^{3}\right.$ molecule $\left.{ }^{-1} \mathrm{~s}^{-1}\right]$} \\
\hline & 3-pentanol & butanol-d9 & 3-pentanol & butanol-d9 \\
\hline 15 April 2011 & $10.08( \pm 0.56)$ & $3.15( \pm 0.06)$ & $11.1( \pm 3.0)$ & $3.48( \pm 0.9)$ \\
\hline 18 April 2011 & $9.63( \pm 0.52)$ & $2.98( \pm 0.06)$ & $10.7( \pm 2.8)$ & $3.30( \pm 0.86)$ \\
\hline $\begin{array}{l}\text { Fit of both } \\
\text { experiments }\end{array}$ & $9.87( \pm 0.38)$ & $3.08( \pm 0.05)$ & $10.9( \pm 2.9)$ & $3.4( \pm 0.88)$ \\
\hline
\end{tabular}

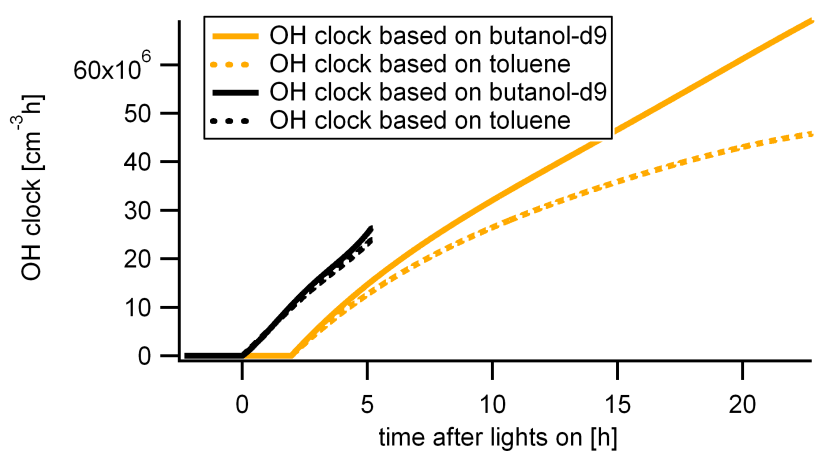

Fig. 6. Comparison of the $\mathrm{OH}$ clocks based on butanol-d 9 and toluene, respectively, as $\mathrm{OH}$ tracers for two experiments. Both tracers were fitted with a polynomial fit of the fourth degree. The fit lasts over $20 \mathrm{~h}$ in the first experiment (orange) and over five hours in a second one (black). After five hours, the toluene based $\mathrm{OH}$ clock reveals a slightly (about $10 \%$ ) lower $\mathrm{OH}$ exposure than the one based on butanol-d9. The discrepancy increases with time and reaches more than $30 \%$ after $20 \mathrm{~h}$. Note that in the 24-h-experiment the tracer (butanol-d9) was injected only $2.5 \mathrm{~h}$ after the lights were turned on.

PSI smog chamber revealed that this systematic error should be less than $3 \%$. Furthermore, we cannot exclude small interferences at the $m / z 71$ (of 3-pentanol) caused by oxidation products of 2-butanone (or less probable oxidation products of butanol-d9). The (opposed) interference of 3-pentanol at 2-butanone's $m / z 73$ was tested and is marginal.

A first application of the butanol-d9 as an $\mathrm{OH}$ tracer was performed in moped exhaust experiments. Figure 6 shows a comparison of the $\mathrm{OH}$ clocks based on butanol-d9 and toluene (a commonly used $\mathrm{OH}$ tracer in emission experiments, e.g. Hennigan et al., 2011) for two moped experiments, by using $k_{\text {toluene }}=5.7 \times 10^{-12} \mathrm{~cm}^{3}$ molecule ${ }^{-1} \mathrm{~s}^{-1}$ at $T=295.15 \mathrm{~K}$ (IUPAC, 2011). The butanol-d9 based $\mathrm{OH}$ clock is slightly higher than the toluene based $\mathrm{OH}$ clock and the discrepancy increases with time. For this later stage of the experiment the butanol-d 9 seems to be clearly superior to the toluene and works even after $20 \mathrm{~h}$ of the experiment. It is possible that an interfering compound at toluene's $\mathrm{m} / \mathrm{z}$ is formed very slowly or injected together with the toluene and leads to the observed discrepancy. Figure 4 clearly shows that this does not happen for $m / z 66$ of butanol-d9.

\section{Summary and conclusion}

Suitable tracers to be measured by PTR-MS were evaluated to establish a (photo-) chemical clock based on $\mathrm{OH}$ exposure. The $\mathrm{OH}$ concentration is obtained by applying an adequate fit to the decay curve of the tracer.

The use of an $\mathrm{OH}$ clock as a "chemical time dimension" might be very useful, particularly for inter-experiment comparisons or between lab studies and atmospheric measurements. The $\mathrm{OH}$ clock is only applicable where $\mathrm{OH}$ is the main oxidant species.

Three $\mathrm{OH}$ tracers were tested during an AP campaign: 3-pentanol, which was injected additionally, 3-pentanone (a direct oxidation product of the reaction of 3-pentanol with $\mathrm{OH}$ ) and PA (an ozonolysis product of AP). The latter reveals no interferences with other compounds at its $\mathrm{m} / \mathrm{z}$, but its initial concentration depends on the amount of AP injected and it is depleted much faster by $\mathrm{OH}$ radicals than 3-pentanol. 3-pentanol interferes at its $m / z 71$ signal with one or more ozonolysis products of $\mathrm{AP}$ and becomes unsuitable in experiments with a high AP concentration. 3-pentanone interferes only little with other compounds and results in $\mathrm{OH}$ concentrations similar to those based on PA.

By using a deuterated hydrocarbon as an $\mathrm{OH}$ tracer chances are higher to avoid these interferences. Butanol-d9 is a very promising $\mathrm{OH}$ tracer which reacts only with $\mathrm{OH}$ and reveals no interferences with other compounds in the (PTR-MS) $m / z$ signal. Its rate constant was determined to be $k_{\text {butanol-d } 9}=3.4( \pm 0.88) \times 10^{-12} \mathrm{~cm}^{3}$ molecule ${ }^{-1} \mathrm{~s}^{-1}$. 
A first application of butanol-d9 as an $\mathrm{OH}$ tracer reveals reasonable and reproducible results. A comparison to toluene, another $\mathrm{OH}$ tracer often used in photochemical processing of emissions, shows a very good agreement up to several hours after the $\mathrm{OH}$ production starts. For a later stage of the experiment the butanol-d 9 seems to be clearly superior to toluene. We would like to point out here that other compounds than n-butanol-d9 would be preferable tracers when analytical techniques other than PTR-MS are used.

Acknowledgements. This work was supported by the Swiss National Science Foundation as well as the EU FP7 project EUROCHAMP-2. Peter F. DeCarlo is grateful for US NSF postdoctoral support. Many thanks to Michel J. Rossi for helpful discussions and general support.

Edited by: J. Abbatt

\section{References}

Berresheim, H., Elste, T., Plass-Dulmer, C., Eisele, F. L., and Tanner, D. J.: Chemical ionization mass spectrometer for long-term measurements of atmospheric $\mathrm{OH}$ and $\mathrm{H}_{2} \mathrm{SO}_{4}$, Int. J. Mass Spectrom., 202, 91-109, 2000.

Blake, N. J., Penkett, S. A., Clemitshaw, K. C., Anwyl, P., Lightman, P., Marsh, A. R. W., and Butcher, G.: Estimates of atmospheric hydroxyl radical concentrations from the observed decay of many reactive hydrocarbons in well defined urban plumes, J. Geophys. Res.-Atmos., 98, 2851-2864, doi:10.1029/92JD02161, 1993.

Brauers, T., Hausmann, M., Bister, A., Kraus, A., and Dorn, H. P.: $\mathrm{OH}$ radicals in the boundary layer of the Atlantic Ocean 1. Measurements by long-path laser absorption spectroscopy, J. Geophys. Res.-Atmos., 106, 7399-7414, 2001.

Brune, W. H.: Stalking the elusive atmospheric hydroxyl radical, Science, 256, 1154-1155, 1992.

Calvert, J. G.: Hydrocarbon involvement in photochemical smog formation in Los Angeles atmosphere, Environ. Sci. Technol., 10, 1163, doi:10.1021/es60122a012, 1976.

Campbell, M. J., Farmer, J. C., Fitzner, C. A., Henry, M. N., Sheppard, J. C., Hardy, R. J., Hopper, J. F., and Muralidhar, V.: Radiocarbon tracer measurements of atmospheric hydroxyl radical concentrations, J. Atmos. Chem., 4, 413-427, 1986.

Donahue, N., Henry, K., Mentel, T., Kiendler-Scharr, A., Spindler, C., Bohn, B., Brauers, T., Dorn, H., Fuchs, H., Tillmann, R., Wahner, A., Saathoff, H., Naumann, K.-H., Moehler, O., Leisner, T., Mueller, L., Hoffmann, T., Salo, K., Hallquist, M., Frosch, M., Bilde, M., Tritscher, T., Barmet, P., Praplan, A., DeCarlo, P., Dommen, J., Prevot, A. S. H., and Baltensperger, U.: Aging of secondary organic aerosol: connecting chambers to the atmosphere, in preparation, 2012.

Dorn, H. P., Brandenburger, U., Brauers, T., Hausmann, M., and Ehhalt, D. H.: In-situ detection of tropospheric OH radicals by folded long-path laser absorption. Results from the POPCORN field campaign in August 1994, Geophys. Res. Lett., 23, $2537-$ 2540, 1996.

Ehhalt, D. H.: Photooxidation of trace gases in the troposphere, Phys. Chem. Chem. Phys., 1, 5401-5408, 1999.
Eisele, F. L. and Tanner, D. J.: Ion-assisted tropospheric OH measurements, J. Geophys. Res.-Atmos., 96, 9295-9308, 1991.

Epstein, S. A. and Donahue, N. M.: The kinetics of tetramethylethene ozonolysis: Decomposition of the primary ozonide and subsequent product formation in the condensed phase, J. Phys. Chem. A, 112, 13535-13541, 2008.

Hennigan, C. J., Sullivan, A. P., Collett Jr., J. L., and Robinson, A. L.: Levoglucosan stability in biomass burning particles exposed to hydroxyl radicals, Geophys. Res. Lett., 37, L09806, doi:10.1029/2010GL043088, 2010.

Hennigan, C. J., Miracolo, M. A., Engelhart, G. J., May, A. A., Presto, A. A., Lee, T., Sullivan, A. P., McMeeking, G. R., Coe, H., Wold, C. E., Hao, W.-M., Gilman, J. B., Kuster, W. C., de Gouw, J., Schichtel, B. A., Collett Jr., J. L., Kreidenweis, S. M., and Robinson, A. L.: Chemical and physical transformations of organic aerosol from the photo-oxidation of open biomass burning emissions in an environmental chamber, Atmos. Chem. Phys., 11, 7669-7686, doi:10.5194/acp-11-7669-2011, 2011.

Hurley, M. D., Wallington, T. J., Bjarrum, M., Javadi, M. S., and Nielsen, O. J.: Atmospheric chemistry of 3-pentanol: Kinetics, mechanisms, and products of $\mathrm{Cl}$ atom and $\mathrm{OH}$ radical initiated oxidation in the presence and absence of $\mathrm{NO}_{\mathrm{x}}, \mathrm{J}$. Phys. Chem. A, 112, 8053-8060, doi:10.1021/jp803637c, 2008.

IPCC: Climate Change 2007: The Physical Science Basis. Contribution of Working Group I to the Fourth Assessment Report of the Intergovernmental Panel on Climate Change, Cambridge University Press, 2007.

IUPAC: Subcommittee for Gas Kinetic Data Evaluation, available at: http://www.iupac-kinetic.ch.cam.ac.uk (last access: 27 September 2011), 2011.

Jenkin, M. E. and Hayman, G. D.: Photochemical ozone creation potentials for oxygenated volatile organic compounds: sensitivity to variations in kinetic and mechanistic parameters, Atmos. Environ., 33, 1275-1293, 1999.

Kleinman, L. I., Springston, S. R., Daum, P. H., Lee, Y.-N., Nunnermacker, L. J., Senum, G. I., Wang, J., Weinstein-Lloyd, J., Alexander, M. L., Hubbe, J., Ortega, J., Canagaratna, M. R., and Jayne, J.: The time evolution of aerosol composition over the Mexico City plateau, Atmos. Chem. Phys., 8, 1559-1575, doi:10.5194/acp-8-1559-2008, 2008.

Kramp, F. and Volz-Thomas, A.: On the budget of $\mathrm{OH}$ radicals and ozone in an urban plume from the decay of $\mathrm{C}_{5}-$ $\mathrm{C}_{8}$ hydrocarbons and $\mathrm{NO}_{\mathrm{x}}$, J. Atmos. Chem., 28, 263-282, doi:10.1023/A:1005821522256, 1997.

Krol, M. and Lelieveld, J.: Can the variability in tropospheric $\mathrm{OH}$ be deduced from measurements of 1,1,1-trichloroethane (methyl chloroform)?, J. Geophys. Res.-Atmos., 108, 4125, doi:10.1029/2002JD002423, 2003.

Lelieveld, J., Dentener, F. J., Peters, W., and Krol, M. C.: On the role of hydroxyl radicals in the self-cleansing capacity of the troposphere, Atmos. Chem. Phys., 4, 2337-2344, doi:10.5194/acp4-2337-2004, 2004.

Lindinger, W., Hansel, A., and Jordan, A.: On-line monitoring of volatile organic compounds at pptv levels by means of protontransfer-reaction mass spectrometry (PTR-MS) - medical applications, food control and environmental research, Int. J. Mass Spectrom., 173, 191-241, 1998.

Lowe, D. C. and Allan, W.: A simple procedure for evaluating global cosmogenic ${ }^{14} \mathrm{C}$ production in the atmosphere using neu- 
tron monitor data, Radiocarbon, 44, 149-157, 2002.

Martinez, R. D., Buitrago, A. A., Howell, N. W., Hearn, C. H., and Joens, J. A.: The near U.V. absorption spectra of several aliphatic aldehydes and ketones at $300 \mathrm{~K}$, Atmos. Environ. Part A, 26, 785-792, 1992.

McKeen, S., Trainer, M., Hsie, E., Tallamraju, R., and Liu, S.: On the indirect determination of atmospheric $\mathrm{OH}$ radical concentrations from reactive hydrocarbon measurements, J. Geophys. Res., 95, 7493-7500, doi:10.1029/JD095iD06p07493, 1990.

McKenna, D. S., Hord, C. J., and Kent, J. M.: Hydroxyl radical concentrations and Kuwait oil fire emission rates for March 1991, J. Geophys. Res.-Atmos., 100, 26005-26025, doi:10.1029/95JD01005, 1995.

Miller, B. R., Huang, J., Weiss, R. F., Prinn, R. G., and Fraser, P. J.: Atmospheric trend and lifetime of chlorodifluoromethane (HCFC-22) and the global tropospheric $\mathrm{OH}$ concentration, J. Geophys. Res.-Atmos., 103, 13237-13248, 1998.

Paulsen, D., Dommen, J., Kalberer, M., Prevot, A. S. H., Richter, R., Sax, M., Steinbacher, M., Weingartner, E., and Baltensperger, U.: Secondary organic aerosol formation by irradiation of 1,3,5trimethylbenzene- $\mathrm{NO}_{x}-\mathrm{H}_{2} \mathrm{O}$ in a new reaction chamber for atmospheric chemistry and physics, Environ. Sci. Technol., 39, 2668-2678, 2005.

Perner, D., Ehhalt, D. H., Patz, H. W., Platt, U., Roth, E. P., and Volz, A.: OH radicals in the lower troposphere, Geophys. Res. Lett., 3, 466-468, 1976.

Poppe, D., Brauers, T., Dorn, H.-P., Karl, M., Mentel, T., Schlosser, E., Tillmann, R., Wegener, R., and Wahner, A.: OH-initiated degradation of several hydrocarbons in the atmosphere simulation chamber SAPHIR, J. Atmos. Chem., 57, 203-214, doi:10.1007/s10874-007-9065-y, 2007.

Prinn, R. G.: Evidence for substantial variations of atmospheric hydroxyl radicals in the past two decades, Science, 293, 10481048, 2001.

Quay, P., King, S., White, D., Brockington, M., Plotkin, B., Gammon, R., Gerst, S., and Stutsman, J.: Atmospheric $(\mathrm{CO})-{ }^{14} \mathrm{C}$ : A tracer of $\mathrm{OH}$ concentration and mixing rates, J. Geophys. Res.Atmos., 105, 15147-15166, 2000.

Roberts, J. M., Fehsenfeld, F. C., Liu, S. C., Bollinger, M. J., Hahn, C., Albritton, D. L., and Sievers, R. E.: Measurements of aromatic hydrocarbon ratios and $\mathrm{NO}_{\mathrm{x}}$ concentrations in the rural troposphere: Observation of air mass photochemical aging and $\mathrm{NO}_{\mathrm{x}}$ removal, Atmos. Environ., 18, 2421-2432, doi:10.1016/00046981(84)90012-X, 1984.

Rohrer, F. and Berresheim, H.: Strong correlation between levels of tropospheric hydroxyl radicals and solar ultraviolet radiation, Nature, 442, 184-187, 2006.

Sage, A. and Donahue, N.: Deconstructing experimental rate constant measurements: Obtaining intrinsic reaction parameters, kinetic isotope effects, and tunneling coefficients from kinetic data for $\mathrm{OH}$ plus methane, ethane and cyclohexane, J. Photoch. Photobio. A, 176, 238-249, 2005.
Salmon, R. A., Schiller, C. L., and Harris, G. W.: Evaluation of the salicylic acid-liquid phase scrubbing technique to monitor atmospheric hydroxyl radicals, J. Atmos. Chem., 48, 81-104, 2004.

Satsumabayashi, H., Kurita, H., Chang, Y. S., Carmichael, G. R., and Ueda, H.: Diurnal variation of $\mathrm{OH}$ radical and hydrocarbons in a polluted air mass during long-range transport in central Japan, Atmos. Environ. A-Gen., 26, 2835-2844, doi:10.1016/0960-1686(92)90021-C, 1992.

Saunders, S. M., Jenkin, M. E., Derwent, R. G., and Pilling, M. J.: Protocol for the development of the Master Chemical Mechanism, MCM v3 (Part A): tropospheric degradation of nonaromatic volatile organic compounds, Atmos. Chem. Phys., 3, 161-180, doi:10.5194/acp-3-161-2003, 2003.

Schlosser, E., Bohn, B., Brauers, T., Dorn, H. P., Fuchs, H., Haseler, R., Hofzumahaus, A., Holland, F., Rohrer, F., Rupp, L. O., Siese, M., Tillmann, R., and Wahner, A.: Intercomparison of two hydroxyl radical measurement techniques at the atmosphere simulation chamber SAPHIR, J. Atmos. Chem., 56, 187-205, 2007.

Schlosser, E., Brauers, T., Dorn, H.-P., Fuchs, H., Häseler, R., Hofzumahaus, A., Holland, F., Wahner, A., Kanaya, Y., Kajii, Y., Miyamoto, K., Nishida, S., Watanabe, K., Yoshino, A., Kubistin, D., Martinez, M., Rudolf, M., Harder, H., Berresheim, H., Elste, T., Plass-Dülmer, C., Stange, G., and Schurath, U.: Technical Note: Formal blind intercomparison of $\mathrm{OH}$ measurements: results from the international campaign HOxComp, Atmos. Chem. Phys., 9, 7923-7948, doi:10.5194/acp-9-7923-2009, 2009.

Singh, H. B., Martinez, J. R., Hendry, D. G., Jaffe, R. J., and Johnson, W. B.: Assessment of the oxidant-forming potential of light saturated hydrocarbons in the atmosphere, Environ. Sci. Technol., 15, 113-119, doi:10.1021/es00083a015, 1981.

Slowik, J. G., Brook, J., Chang, R. Y.-W., Evans, G. J., Hayden, K., Jeong, C.-H., Li, S.-M., Liggio, J., Liu, P. S. K., McGuire, M., Mihele, C., Sjostedt, S., Vlasenko, A., and Abbatt, J. P. D.: Photochemical processing of organic aerosol at nearby continental sites: contrast between urban plumes and regional aerosol, Atmos. Chem. Phys., 11, 2991-3006, doi:10.5194/acp-11-29912011, 2011.

Taira, M. and Kanda, Y.: Continuous generation system for lowconcentration gaseous nitrous-acid, Anal. Chem., 62, 630-633, 1990.

Tritscher, T., Dommen, J., DeCarlo, P. F., Gysel, M., Barmet, P. B., Praplan, A. P., Weingartner, E., Prévôt, A. S. H., Riipinen, I., Donahue, N. M., and Baltensperger, U.: Volatility and hygroscopicity of aging secondary organic aerosol in a smog chamber, Atmos. Chem. Phys., 11, 11477-11496, doi:10.5194/acp11-11477-2011, 2011.

Wallington, T. J., Dagaut, P., Liu, R., and Kurylo, M. J.: Rate constants for the gas phase reactions of $\mathrm{OH}$ with $\mathrm{C}_{5}$ through $\mathrm{C}_{7}$ aliphatic alcohols and ethers: Predicted and experimental values, Int. J. Chem. Kinet., 20, 541-547, 1988. 